\title{
ORGANIZATION OF ENVIRONMENTAL MONITORING IN THE CASPIAN SEA
}

\author{
Nazila Ali Ragimova ${ }^{1}$, Vugar Hajimahmud Abdullayev ${ }^{2}$, Vasila Soltanaga Abbasova ${ }^{3}$ \\ ${ }^{1}$ Department “Computer Engineering”, Azerbaijan State Oil and Industry University, Baku, Azerbaijan \\ ${ }^{2}$ Department "Computer Engineering", Azerbaijan State Oil and Industry University, Baku, Azerbaijan \\ abdulvugar@mail.ru \\ ORCID: http://orcid.org/0000-0002-3348-2267 \\ ${ }^{3}$ Department “Computer Engineering”, Azerbaijan State Oil and Industry University, Baku, Azerbaijan
}

A R T I L E IN F O
Article history:
Received date 20.03 .2020
Accepted date 21.04 .2020
Published date 30.04 .2020
Section:
Information Technology \& Systems
D O I
10.21303/2313-8416.2020.001277
K E Y W O R D S
information systems
environmental monitoring
Caspian Sea
ecology
monitoring

\section{ABSTRACT}

The object of research is ecological monitoring of the Caspian Sea. This article addressed the objectives and components of environmental monitoring. It also describes the objectives for the establishment of a Unified State Environmental Monitoring System. Special attention is paid to the structure of the environmental network monitoring system, which consists of three levels: low, medium and high.

One of the main problems is the establishment of the Unified State Environmental Monitoring System of the Caspian Sea. This article considered the main functions and objectives of the Unified State Environmental Monitoring System. Here are also discussed the computing center of the environmental monitoring system and its functions and components. The research used three main components for environmental data processing: database management systems, geographic information system and integrated software packages. Examples of a computer system of environmental monitoring include: ArcGIS, MapInfo, ArcView and OCEAN.

The main scientific results of this research are the main functions, objectives and components of environmental monitoring of the Caspian Sea to reduce pollution levels.

The obtained results can be used to optimize the characteristics of environmental information systems, which are used to organize environmental monitoring.

Innovative technological product of this research is the development of an algorithm for the organization of environmental monitoring of the Caspian Sea. It will allow ecologists to monitor the environmental situation of the Caspian Sea and further improve it.

The obtained innovative technological product will be useful for carrying out environmental monitoring of the most contaminated section of the water basin, and more precisely for monitoring the scale of pollution and further improving the environmental situation of the water area.

(C) The Author(s) 2020. This is an open access article under the CC BY license http://creativecommons.org/licenses/by/4.0).

\section{Introduction}

\section{1. Subject of research}

The term environmental monitoring refers to the system of monitoring, monitoring, evaluating the state of the environment, forecasting and information support for the preparation and adoption of management decisions. The purpose of environmental monitoring is to provide environmental management and environmental safety information management [1].

Among the measures to stabilize the environmental situation, special attention is paid to the establishment of the Unified State Environmental Monitoring System (USEMS). Its main purpose is to provide information about environmental situation to public authorities and nature users in different regions of the country, information support for decision-making in the field of environmental protection and environmental security [2].

USEMS should provide a central scientific and technical policy in the field of environmental monitoring:

- Coordination of the development and implementation of environmental monitoring programs;

- Regulation and control of the collection and processing of real data; 
- Maintenance of information, creation of special data bank;

- Activity on assessment and forecasting of the health status of the population as a result of the response of environmental objects, natural resources, ecosystems and anthropogenic impact;

- Access to environmental information for a wide range of consumers [3].

The results of the environmental monitoring constitute the data base (data bank) of the IMC (environmental database), which allows the use of computers to collect, store, process and analyze information. The information provision of the IMC, in turn, is the basis for the management of nature protection activities and the implementation of resource protection policies. Monitoring awareness depends to a large extent on the level of technical equipment (service level), so the whole set of control standards should be taken as a benchmark - volume, periodicity, accuracy and accuracy. An important prerequisite for providing the required information is the use of computers and monitoring tools [4].

The overall structure of surface monitoring network hardware in the environmental monitoring system includes:

1. For the low level of the monitoring network:

- Air and water stationary stations;

- Mobile and stationary laboratories on atmospheric, water, soil and abdominal conditions;

- Mobile Waste and Disposal Control Stations;

- Inspection services;

- Data acquisition services.

The number of stationary and mobile stations and stations is determined as a result of surveys, based on estimates based on existing models of specific natural-technical geosystem (or natural-terrain complex), as well as on the experience gained during environmental observations.

2. For Medium Network: Centers for data collection and processing, obtained on lower networks, differing in their complexity and complexity of issues.

3. For high-quality network: Users of information from the collection and processing centers [5].

The main components of the monitoring network include transmitters and analyzers, data loaders, data transfer devices and so on. In a hierarchical network of surface measurements, information processing computing tools are practically used at all levels of the network. In stationary and mobile stations, the data loader manages not only the analyzers but also the initial processing of the data collected. Local and central computing centers calculate environmental pollution levels for key and auxiliary ingredients, model maps, forecasts, find possible sources of contamination, and so on [5].

The Pollution Monitoring Network Computing Center performs the following functions:

- Operation of surface measuring network in operational, storm mode and capability control mode;

- Collection of information from stationary pollution control stations and mobile laboratories;

- Creation of a database of operative and long-term storage of information related to ensuring the reliable storage of information and its protection against unauthorized access;

- Processing of information for estimation of forecasts, general pollution status for the purpose of integrated assessment of ecological state of environment, etc .;

- Schedule table, cartographic material, etc. preparation and provision of information on contamination in the form of;

- Transfer of information to the main computing center automatically.

Surface measurement data network from environmental monitoring stations solves the following issues:

- Regular data transfer from stationary stations and mobile laboratories (once every $10 \mathrm{mi}-$ nutes, 30 minutes, 1 hour, etc.);

- Transmission of information on excitement and accidents from the population;

- Transfer of information to the users of the computing center through the communication channels (executive power, population, etc.).

Comprehensive environmental monitoring system information should include:

- Regular structure of information flows (input, internal, output);

- Own information infrastructure infrastructure; 
- Methods of data collection from stationary and mobile stations;

- Methods of transmitting data from different levels, including leaders;

- Processing of environmental data and methods of calculating integrated indicators;

- Wastewater identification methodology;

- Structure of the network of user organizations and services.

The software of the integrated environmental monitoring network includes:

- Advanced operating systems;

- Standard database;

- Cartographic and Graphic Support;

- Monitors for data collection management.

One of the key components of environmental monitoring is sampling points. Sampling stations are being set up at observation points for this purpose. After sampling, the laboratory performs regular and comprehensive analyzes. Our specialists regularly take part in the expeditions. The person responsible for monitoring the results is entrusted with the monitoring. After the monitoring, an authorized person shall draw up an appropriate act. After the ingredients are analyzed, the preliminary results are compared with the results obtained and placed in the laboratory's logbook. There is a great need for the use of modern induction technologies because of the difficulty of hand-held data analysis to classify results over the years. ISs are used for this purpose, and the results of monitoring and data from their analysis are posted on the database [6].

\section{2. Description of a problem}

Information System (IS) is a complex of technical, software, linguistic and methodological tools that ensure the collection, storage, processing and delivery of information related to the application area. Techniques include, in addition to a computer, tools for transferring, recording and displaying information. The IS is created to meet the information needs of different users within a specific topic area.

Information systems can be designed individually or as part of any automated system. In the first case, it is used as an information inquiry system to meet the needs of individuals or collectives for information. In the second case, the automated system will provide information and reference services to the users and will serve as an information system for the automated system.

Rapid development of information technologies has led to further expansion of their application areas.

\section{3. The Intended Way to Solve the Problem}

One of the areas of application of information systems is Ecology. The information systems used in ecology provide information about the environmental situation and facilitate and accelerate appropriate decisions to prevent environmental pollution in a timely manner. With the help of these systems, it is also possible to obtain new knowledge by analyzing and analyzing information, revealing relevant laws. Effective application of information systems enables to make more accurate forecasts and eliminate possible mistakes in management.

\section{Aim of research}

The aim of this research is as follows:

- comparative analysis of environmental information systems on the market to select suitable for monitoring the Caspian Sea;

- determining the monitoring elements of the Caspian Sea;

- specifies the appropriate database model to be applied to the selected system.

\section{Materials and Methods}

Environmental Information System is a software and technical complex based on a multidimensional description of the observations, including the results of the monitoring and the environmental impact assessment. The data processing in this complex is realized through 3 main components:

- Database Management System (DBMS) - such as MS Access, MS Visual FoxPro, Paradox, dBase, InterBase, MS SQL Server, Oracle, SyBase, etc. 
- Geographical Information System (CIS), which systematizes data on electronic maps describing the coordinates of the segments organized into different layers, for example: ArcInfo, MapInfo, ArcView, Manifold System, ObjectLand, Map-2000, etc.

- Integrated software packages (IPPs) that perform visual and graphic analysis of assessment methods that affect ecosystems using mathematical methods, depending on the problem.

A single information system is built on the basis of the listed components. The following TPPs are used for IS installation.

- ArcGIS. Software products are widely distributed around the world as the most optimal solution for the creation and effective management of information systems in large government and business structures, as well as for the establishment of corporate geographic information systems. ArcGIS is the perfect tool for creating and publishing maps, software models, web browsers with ease, integrating with other systems, managing geographical data, analyzing, planning and making the right decisions [7].

- MapInfo is the most common software for creating CIS. It is a universal software product and has great potential for graphic drawing and traditional printing of these images. Uses thematic and graphically modified information, performs work for documentation, i. e. printing electronic maps in the traditional form, writing legendary descriptions and designing all necessary parts for drawing in accordance with international standards [8].

- ArcView The geographical information system ensures the implementation of high-level geoinformation systems created by ESRI. The ArcView environment is created for the development of CIS technologies. This software product includes ecology, telecommunications, etc. It has been successfully applied in the field and includes software tools with universal tools for creating digital maps. ArcView provides an interactive interface with various sets of commands to work with cartographic and attribute data: database creation and configuration, graphical and attribute data import, export and export of geographical information, reporting [9].

The listed software packages mainly perform the following functions:

- Accumulation of spatial data using GPS systems and other measuring devices, field research, precise measurements.

- Design, automation of spatial data infrastructure (information system) and creation of features based on object-oriented GIS analysis, obtaining special analyzes and reports.

- Updating, structuring, rearranging spatial data and exchanging and sharing geospatial data (stored on special storage devices) with other databases.

- Data modeling and design and creation of spatial database with special access.

- Development of independent and special-purpose GIS programs, creation of specialized, specialized corporate GIS [10].

Environmental Impact Assessment Geographical Information Systems (CIS), designed to automate analyzes of environmental monitoring tools, present its complex and multifunctional aspects. Environmental information systems have the potential to expose environmental problems from large and small distances, to monitoring environmental quality, to accurately identify the source of environmental problems and to make predictions of development. Remote sensing technologies, satellites and even mobile phones help environmentalists to monitor and manage the environment, reduce emissions and increase energy efficiency. The creation of such systems is based on a combination of complex data and knowledge that can be difficult to organize.

Recently, international organizations have been successfully creating electronic collections related to documentary information retrieval systems in the area of water ecology and biodiversity. The list of marine life and OCEAN bibliographic information systems is one of the most promising projects funded by the Alfred Sloan Foundation.

"OCEAN" The environmental information systems were based on actual data from the Naval Research Laboratory of the Russian Academy of Sciences. The development of a single oceanic information system is based on oceanographic knowledge.

In order to organize intellectual search in the system, a list of terms specific to the subject area was first followed, and then a semantic relationship between these terms was studied. A dictionary, that is, an ontology, has been created to reflect these semantic relationships. By searching 
on an ontology, the search engine was able to achieve the search integration and the query was implemented in the dialogue mode.

Expanding document collections in the knowledge base of the system is based on creating backups. In this case, the visibility of the images searched in the database is also ensured. One of the positive aspects of the system is that images here are logically linked to a database that stores documentary information.

The concept, based on environmental and geographic information systems, provides opportunities to effectively solve complex problems.

\section{1. Experimental procedures}

Groundwater monitoring is carried out by the Ministry of Ecology and Natural Resources. Groundwater monitoring networks are available all over the country, and the monitoring system is installed in over 800 wells, springs and wells. Monitoring studies examine the level, consumption, temperature and quality of groundwater.

In addition to the monitoring network of the Ministry of Ecology and Natural Resources, there is a special network of «Azersu» OJSC, and a special network of irrigation and reclamation facilities in irrigated areas.

The Caspian Sea is unique in its physical and geographical characteristics and is characterized by large hydrocarbon reserves. The oil sector plays a great role in the socio-economic life of our republic.

Apart from the alarming level of problems in the Caspian Sea, pollution of marine waters and associated environmental degradation is one of the most important issues of recent times. The rich natural resources and the importance of healing have historically caused a large number of people to live around it. The main sources of pollution in the Caspian Sea are pollutants from cities and industrial facilities located in its basin, shores and aquatories, from maritime transport and oil fields.

At present, the ecological situation in the Caspian Sea is very tense. The problem is more acute in the marine shelf zone, where dead zones have already been established. In some places, the cost of pollutants exceeds the norm by 10-20 times.

The following monitoring functions are carried out using the best available experience in the ecology of the Caspian Sea:

- Monitoring the organization of activity programs in the field of protection, restoration and reproduction of biological resources of the Caspian Sea.

- Determination of norms and limits for increase and discharge of pollutants by the Caspian Sea, floating means, household and industrial facilities.

- Determination of ecologically superior areas of ecological disasters, zones of ecological disaster in the Caspian Sea.

- Determining the ecological conditions of the Caspian Sea, ecologically superior areas of ecological disaster zones.

- Determining anthropogenic impact on the Caspian coastline, its borders and mode of use.

- Periodic improvement of existing methods for the prevention of extreme environmental pollution caused by accidents at sea.

- Blasting, deepening operations, extraction of minerals, insulators, cables, oil and gas pipelines, etc. Monitoring of the negative impacts of the environment as a result of smoking.

- Determination, registration and dynamics of harmful substances emitted by transport and other floating vehicles and facilities into the environment.

- Commissioning of appropriate facilities for cleaning pollutants discharged into the environment, monitoring the efficiency of their operations, sources of pollution.

- To study the anthropogenic impact of biological resources on the Caspian Sea and its coastline and make forecasts.

Comprehensive monitoring is being carried out to prevent environmental pollution of the Caspian Sea. Pollution Monitoring of the Caspian Sea (Lake) part of the Republic of Azerbaijan is to identify the sources of pollution, quantitative and qualitative indicators of pollutants discharged, to assess the contamination status of the sea and to assess the status of the sea. 
The purpose of monitoring is to provide seawater, fluorine, and all types of wastes (liquid, gas, solid, etc.) that are formed in the offshore and coastal areas, either directly or indirectly (through collector, canal, river, etc.) in anthropogenic impacts on the Caspian Sea. collecting data by analyzing and investigating its impact on the fauna and other water bodies and achieving mitigation measures. Monitoring was carried out at the oil companies of the State Oil Company of the Republic of Azerbaijan to study the oil pollution of the Caspian Sea and its coastline, in the Navy, at the ports, as well as in the coverage of foreign companies alongside local companies.

Monitoring of pollution of the Caspian Sea (lake) includes:

- Identification of sources of sea pollution.

- Continuous monitoring of the physical, chemical and hydrobiological indicators of water and sediment contamination levels in areas that are most heavily contaminated in the sea sector of the Republic of Azerbaijan, in spa and recreational areas.

- Investigation of time and spatial dynamics of pollutant concentrations and the study of the dependence of these processes on the natural circulation, the hydrometeorological regime of the sea and the characteristics of economic activities.

- Conducting regular and regular surveys to assess the level of contamination of water and sediment in the open sea, coastal areas and along the maritime boundary.

- Observations on the background of sea water and bottom sediments are carried out in the open sea and at long-term oceanic (marine hydrometeorological) stations in some coastal areas that are less polluted.

Physico-chemical, chemical, biological, ecotoxicological and microbiological analyzes of water, sediment, sludge and drilling samples taken as a result of the monitoring are conducted. Laboratory specialists take part in environmental expeditions organized in the Caspian Sea by the local and foreign oil companies, international organizations and the Ministry of Ecology and Natural Resources, and analyze water and bottom sediment samples in parallel.

\section{Results and Discussion}

First, the criteria to be met by the future system must be formulated to begin with. After that, analyze existing systems on the market and select an environmental information system suitable for the specified criteria.

After the IS is selected, it is implemented, and also, immediately or simultaneously, it is necessary to create a relational database where all important data will be stored.

Before operation it is necessary to test all IE components and make sure that the processes of information collection, storage and processing are carried out correctly. After all the necessary tests have been carried out, the environmental information system can be started to operate.

\section{Discussion}

Due to the increasing level of pollution of the world 's oceans, it makes sense to create USEMS. The relevant public authority should monitor the operation of this system, as it is expensive, in some places economically unfavourable and has a long-term perspective. The main functions and components of USEMS were considered to organize environmental monitoring. On the basis of this, an algorithm for the organization of environmental monitoring was developed.

\section{Conclusions}

This article discussed environmental monitoring and the Unified State Environmental Monitoring System, more precisely their objectives, functions and components. Here are also discussed the existing geographic information systems: ArcGIS, MapInfo, ArcView and OCEAN, including their features. This was followed by an example of how this monitoring was carried out and its criteria and main components were identified.

The resulting algorithm as a result of the research will allow to optimize environmental monitoring of the Caspian Sea. This made it possible to identify sources of pollution, assess the state of the coastline and assess the biodiversity of the Caspian Sea. This monitoring will allow ecologists to monitor the environmental situation of the Caspian Sea and further improve it. 


\section{References}

[1] El-Gayar, O., Fritz, B. D. (2006). Environmental Management Information Systems (EMIS) for Sustainable Development: A Conceptual Overview. Communications of the Association for Information Systems, 17. doi: http://doi.org/10.17705/1cais.01734

[2] Schaltegger, S., Bennett, M., Burritt, R. L., Jasch, C. (2008). Enviromental Management Accounting for Cleaner Production. Springer. doi: http://doi.org/10.1007/978-1-4020-8913-8

[3] Tziavos, I. N., Alexandridis, T. K., Aleksandrov, B., Andrianopoulos, A., Doukas, I. D., Grigoras, I. et. al. (2016). Development of a Web-based GIS monitoring and environmental assessment system for the Black Sea: application in the Danube Delta area. Environmental Monitoring and Assessment, 188 (8). doi: http://doi.org/10.1007/s10661-016-5492-Z

[4] Wawrzyniak, Z., Paczesny, D., Manczuk, M., Zatonoski, W. (2011). Application of advanced data collection and quality assurance methods in open prospective study - a case study of PONS project. Annals of agricultural and environmental medicine. AAEM, 18 (2), 207-214.

[5] Šećerov, I., Dolinaj, D., Pavić, D., Milošević, D., Savić, S., Popov, S., Živanov, Ž. (2019). Environmental Monitoring Systems: Review and Future Development. Wireless Engineering and Technology, 10 (1), 1-18. doi: http://doi.org/10.4236/wet. 2019.101001

[6] Gupta, R. (2014). Role of Environmental Monitoring and Microbiological Testing during Manufacture of Sterile Drugs and Biologics. American Pharmaceutical Review, 17 (6), 46-55.

[7] Mittapalli, G., Gorthi, K., Arathiand, S. (2011). Development of Spatial Analyst toolbar in ArcGIS. Journal of Advances in Remote Sensing and Gis, 1 (1).

[8] Buldakov, I. V. (2017). Thematic and User-Defined Map Signs Conversion from MapInfo to ArcGIS. Vestnik NSU. Series: Information Technologies, 15 (2), 13-19. doi: http://doi.org/10.25205/1818-7900-2017-15-2-13-19

[9] Hossain, M., Masud, M. Evaluating Software Usability of Geographic Information System. Available at: https://www. researchgate.net/publication/228345628_Evaluating_Software_Usability_of_Geographic_Information_System

[10] Pundt, H., Brinkkötter-Runde, K. (2000). Visualization of spatial data for field based GIS. Computers \& Geosciences, 26 (1), 51-56. doi: http://doi.org/10.1016/s0098-3004(99)00033-3 